\title{
Radiotherapy in the treatment of postoperative chylothorax
}

\author{
Zsolt Sziklavari ${ }^{1}$, Michael Allgäuer ${ }^{2}$, Georg Hübner², Reiner $\mathrm{Neu}^{3}$, Michael Ried ${ }^{3}$, Christian Grosser ${ }^{1}$, Tamas Szöke ${ }^{1}$, \\ Rudolf Schemm ${ }^{1}$ and Hans-Stefan Hofmann ${ }^{1,3^{*}}$
}

\begin{abstract}
Background: Chylothorax is characterized by the presence of chyle in the pleural cavity. The healing rate of nonoperative treatment varies enormously; the maximum success rate in series is $70 \%$. We investigate the efficacy and outcomes of radiotherapy for postoperative chylothorax.

Methods: Chylothorax was identified based on the quantity and quality of the drainage fluid. Radiation was indicated if the daily chyle flow exceeded $450 \mathrm{ml}$ after complete cessation of oral intake. Radiotherapy consisted of opposed isocentric portals to the mediastinum using $15 \mathrm{MV}$ photon beams from a linear accelerator, a single dose of 1-1.5 Gy, and a maximum of five fractions per week. The radiation target area was the anatomical region between $\mathrm{TH} 3$ and $\mathrm{TH} 10$ depending on the localization of the resected lobe. The mean doses of the ionizing energy was $8.5 \mathrm{~Gy} \pm 3.5 \mathrm{~Gy}$.

Results: The median start date of the radiation was the fourth day after chylothorax diagnosis. The patients' mediastinum was radiated an average of six times. Radiotherapy, in combination with dietary restrictions, was successful in all patients. The median time between the end of the radiation and the removal of the chest tube was one day. One patient underwent wound healing by secondary intention. The median time between the end of radiation and discharge was three days, and the overall hospital stay between the chylothorax diagnosis and discharge was 18 days (range: 11-30 days). After a follow-up of six months, no patient experienced chylothorax recurrence.

Conclusions: Our results suggest that radiotherapy in combination with dietary restriction in the treatment of postoperative chylothorax is very safe, rapid and successful. This novel interventional procedure can obviate repeat major thoracic surgery and shorten hospital stays and could be the first choice in the treatment of postthoracotomy chylothorax.
\end{abstract}

Keywords: Chylothorax, Radiotherapy, Postoperative complication

\section{Background}

Chylothorax is characterized by the presence of chyle, which is rich in triglycerides and chylomicrons, in the pleural cavity. There are four typical causes of chylothorax: tumor, trauma, idiopathic and miscellaneous. Chylothorax also complicates up to $3 \%(0,26-3 \%)$ of intrathoracic procedures (not including esophagus surgery), especially in patients undergoing radical mediastinal lymph node

\footnotetext{
* Correspondence: hans-stefan.hofmann@ukr.de

'Department of Thoracic Surgery, Hospital Barmherzige Brüder Regensburg,

Prüfeningerstraße 86, 93049, Regensburg, Germany

${ }^{3}$ Department of Thoracic Surgery, University Regensburg,

Franz-Josef-Strauss-Allee 11, 93053, Regensburg, Germany

Full list of author information is available at the end of the article
}

dissection. Thoracic surgery involving esophageal surgery has a maximum chylothorax incidence of $4 \%$ [1]. In cases of chronification, malnutrition and immunologic complications can occur, and a mortality rate of up to $50 \%$ has been reported [2]. Currently, the morbidity and mortality associated with chylothorax have improved due to the implementation of more aggressive management strategies.

Conservative treatment of chylothorax includes chest tube drainage and enteral/parenteral dietary management, which is based on the restriction of long chain fatty acids and triglycerides. The daily output from the chest tube is most likely the most important indicator of the patient's

\section{Biomed Central}

(c) 2013 Sziklavari et al.; licensee BioMed Central Ltd. This is an Open Access article distributed under the terms of the Creative Commons Attribution License (http://creativecommons.org/licenses/by/2.0), which permits unrestricted use, distribution, and reproduction in any medium, provided the original work is properly cited. 
chance of success with conservative treatment. The healing rate of non-operative treatment varies enormously.

If drainage remains $>1000 \mathrm{ml} /$ day, surgical intervention has been shown to reverse the adverse effects of chyle [3]. This management strategy decreased the mortality rates for chylothorax [4]. However, especially in cases of postoperative chylothorax, repeated surgical procedures were necessary due to a complicated clinical course. Repeat operations are necessary in up to $72 \%$ of cases and include video-assisted thoracic surgery (VATS) and repeat thoracotomy for pleurectomy, talc pleurodesis or ligation of the thoracic duct [3].

Because of the time-consuming conservative treatment and the limited results with interventional and surgical treatment we sought to develop an alternative therapy for postoperative chylothorax. Due to the good outcomes in the treatment of inguinal lymph fistulas with radiotherapy [5] and some well documented case reports describing the successful management of malignant chylothorax with radiotherapy [6,7], we investigated the efficiency and outcome of radiotherapy for postoperative chylothorax.

\section{Methods}

In this retrospective study, we investigated seven patients with postoperative chylothorax who were treated at our department between April, 2010 and October, 2011. Chylothorax was identified based on the quantity and milky aspect of the drainage fluid, and the diagnosis was confirmed based on the documentation of elevated triglyceride levels $(>110 \mathrm{mg} / \mathrm{dl})$ in the pleural fluid.

The mean age of the patients (male $=4$, female $=3$ ) was 59 years (range: 27 to 74 years). The cause of chylothorax in all seven cases was thoracotomy. In four of the cases, chylothorax developed following antero-lateral thoracotomy for a lobectomy $(\mathrm{n}=4)$, and in 2 cases, chylothorax developed following a wedge resection procedure $(n=2)$; all six of these cases also involved radical lymphadenectomy. One patient underwent a sternotomy for thymectomy without lymph node dissection. A left-sided chylothorax was observed in two patients, and a rightsided chylothorax was observed in five patients. The patient demographics and lung pathologies are summarized in Table 1.

All patients had chest tubes placed after their initial operation. Patients 1, 4 and 7 with highly chyle flow had complete cessation of oral intake (parenteral alimentation), whereas the other four patients were restricted to a fat free diet (exception: medium-chain triglyceridesMCT). Moderate chest tube suction at $20 \mathrm{~cm} \mathrm{H}_{2} \mathrm{O}$ was applied. Radiation was indicated if the daily chyle flow exceeded $450 \mathrm{ml}$ after complete oral intake cessation and total parenteral nutrition or fat free diet. A lymphangiography for the identification of the leakage was not performed. The radiotherapy was administered with the written informed consent of the patients. Radiotherapy consisted of opposed isocentric portals to the mediastinum using $15 \mathrm{MV}$ photon beams from a linear accelerator (Synergy, Elekta Stockhom, Sweden), a single dose of 1-1.5 Gy, and a maximum of five fractions per week. The target radiation area was the posterior mediastinum between TH3 and TH10 depending on the localization of the resected lobe. The mean doses of the ionizing energy was $8.5 \mathrm{~Gy} \pm 3.5 \mathrm{~Gy}$. Monitoring of the serum electrolytes, lymphocyte count, albumin, total protein and the patients' weight was performed.

The medical records were retrospectively reviewed and the following information was collected: patient age, patient sex, clinical course, side of thoracotomy, etiology, radiotherapy course, mean quantity of daily chyle, duration of drainage, length of hospital stay and outcome. All patients were followed up. The mean follow-up period was 6 months (3-16 months). Because of the skewed distributions, we mostly used the median as a location parameter in descriptive statistics. The outcomes are summarized in Table 2 .

\section{Results}

At our institution, postoperative chylothorax occurred in $2.8 \%$ of the cases involving thoracic surgery with radical systematic lymphadenectomy. The manifestation of the chylothorax occurred between the $1^{\text {st }}$ and $14^{\text {th }}$ postoperative day (median, $2^{\text {nd }}$ day). The mean pre-radiation daily chyle flow was $800 \mathrm{ml} /$ day (range: $450-1700 \mathrm{ml} /$ day) with a mean concentration of triglycerides of 224 $\mathrm{mg} / \mathrm{dl}$ (range: $121-1185 \mathrm{mg} / \mathrm{dl}$ ).

The median start date of the radiation was on the fourth day (range second- $21^{\text {st }}$ day) after diagnosis of the chylothorax. Treatment of the first patient was delayed until the $21^{\text {st }}$ postoperative day because the radiooncologists were hesitant due to the uncertain outcomes of this novel treatment modality. Radiotherapy, including enteral or parenteral, no-fat diet was successful in all patients. The mediastinum of the patients was radiated a mean of six times (range 3-10 times). During radiotherapy and diet, the mean concentration of triglycerides decreased to $157 \mathrm{mg} / \mathrm{dl}$ (range 61-642 ml/day). After radiation, the mean chyle flow was $90 \mathrm{ml} / \mathrm{dl}$ (range: 0$150 \mathrm{ml} /$ day) (Figure 1). The median time between the end of the radiation therapy and the removal of the chest tube was one day (range: $1-8$ days).

The enteral or parenteral no-fat diet was continued until the end of radiotherapy. One day later, the lymphatic system was activated with a fatty meal. If the drainage fluid remained non-chylous and did not increase, the chest tube was removed.

The majority of the patients had no major complications after radiation. One patient underwent wound 


\section{Table 1 Patient demographics}

\begin{tabular}{|c|c|c|c|c|c|c|c|}
\hline & Patient 1 & Patient 2 & Patient 3 & Patient 4 & Patient 5 & Patient 6 & Patient 7 \\
\hline Age & 74 & 70 & 57 & 59 & 47 & 38 & 62 \\
\hline Sex & Male & Male & Female & Male & Male & Female & Male \\
\hline Karnofsky-Index $<70 \%$ & Yes & No & Yes & No & No & No & Yes \\
\hline Histology & NSCLC Stage IA & NSCLC Stage II A & NSCLC Stage III A & Pseudotumor & Metastasis & Thymoma & Metastasis \\
\hline Neoadjuvant Therapy & No & No & Yes & No & Yes & No & Yes \\
\hline Localisation & Right upper lobe & Left lower lobe & Left lower lobe & Left lower lobe & Right midle, lower lobe & Mediastinum & Right upper lobe \\
\hline Primary Operation & Lobectomy & Lobectomy & Lobectomy & Lobectomy & Wedge- resection & Thymectomy & Wedge- resection \\
\hline Lympadenectomy & Yes & Yes & Yes & Yes & Yes & No & Yes \\
\hline Diagnosis, postoperative day & $14^{\text {th }}$ & $6^{\text {th }}$ & $2^{\text {nd }}$ & $3^{\text {rd }}$ & $1^{\text {st }}$ & $2^{\text {nd }}$ & $2^{\text {nd }}$ \\
\hline Cholesterol level mg/dl of drainage fluid at Diagnosis ${ }^{\circ}$ & 35 & 42 & 45 & 48 & 190 & 65 & 37 \\
\hline Triglyceride level of drainage fluid $\mathrm{mg} / \mathrm{dl}$ at Diagnosis ${ }^{\circ}$ & 121 & 491 & 371 & 123 & 186 & 1185 & 224 \\
\hline
\end{tabular}


Table 2 Therapy and outcomes

\begin{tabular}{|c|c|c|c|c|c|c|c|}
\hline & Patient 1 & Patient 2 & Patient 3 & Patient 4 & Patient 5 & Patient 6 & Patient 7 \\
\hline Begin of Radiation after Diagnosis (d) & $9^{\text {th }}$ & $4^{\text {th }}$ & $4^{\text {th }}$ & $2^{\text {nd }}$ & $11^{\text {th }}$ & $21^{\text {st }}$ & $3^{\text {rd }}$ \\
\hline Number of Radiations ( $\mathrm{n}$ ) & 6 & 8 & 8 & 5 & 3 & 3 & 10 \\
\hline Radiation-Energy (Gy) & 6 & 12 & 8 & 5 & 9 & 9 & 10 \\
\hline Max..Flow before Radiation (ml/d) & 1100 & 450 & 850 & 800 & 710 & 450 & 1700 \\
\hline Max. Flow after Radiation $(\mathrm{ml} / \mathrm{d})$ & 0 & 150 & 90 & 90 & 200 & 220 & 0 \\
\hline Day of the chest tube removal after Radiation & $1^{\text {st }}$ & $1^{\text {st }}$ & $1^{\text {st }}$ & $2^{\text {nd }}$ & $8^{\text {th }}$ & $7^{\text {th }}$ & $1^{\text {st }}$ \\
\hline Length of hospital after Diagnosis (d) & 23 & 18 & 15 & 11 & 21 & 30 & 16 \\
\hline Length of hospital after Radiation (d) & 5 & 3 & 2 & 3 & 13 & 7 & 2 \\
\hline Cholesterol after Radiation, mg/dl & 35 & n.a. & n.a. & 67 & n.a. & 54 & 50 \\
\hline Triglyceride after Radiation mg/dl & 121 & n.a. & n.a & 40 & n.a & 126 & 74 \\
\hline Re-Chylothorax & No & No & No & No & No & No & No \\
\hline Complications & - & - & - & - & Urosepsis & - & - \\
\hline
\end{tabular}

healing by secondary intention, and another patient developed urosepsis that was not related to the treatment. The median time between the end of the radiation therapy and discharge was three days (range: 2-13 days), and the overall hospital stay between the diagnosis of chylothorax and discharge was 18 days (range: 11-30 days). After a mean follow-up of six months, no patient experienced chylothorax recurrence.

\section{Discussion}

The present study is the first to show, in a significant number of patients, that postoperative chylothorax can be effectively healed with a combination of radiotherapy and diet.

Chylothorax is a rare condition that results from thoracic duct injury and usually occurs on the right side. The most common causes of chylothorax are malignancy and trauma [8].

Currently, thoracic surgery has replaced physical injury as the leading cause of trauma; esophageal surgery accounts for most of these cases with a maximum incidence of $4 \%$ [1]. The incidence of postoperative chylothorax following thoracic surgery without esophageal surgery varies between $0,26 \%$ and $3 \%$ (Table 3 ).

Mediastinal lymphadenectomy seems to be responsible for the higher incidence of postoperative chylothorax after lung cancer resection [9-12,15]. Patients who underwent only sampling of the mediastinal lymph nodes did not develop chylothorax $[9,10]$. Bollen et al. [9] and Izbicki et al. [10] reported a postoperative chylothorax rate at the beginning of systemic radical mediastinal lymph node dissection of $3 \%(n=2 / 65)$ and $1.2 \%(n=1 / 84)$, respectively. In a larger group of patients $(\mathrm{n}=1110)$ undergoing pulmonary resection and systematic mediastinal lymph node dissection for lung cancer, Shimizu et al. reported 27 patients (2.4\%) with postoperative chylothorax [12]. Zabeck et al. reported, that in 25 of their 26 postoperative chylothorax cases, complete mediastinal lymph node dissection was performed [15]. In six of our seven cases, complete mediastinal lymph node dissection was performed. At our institution, postoperative chylothorax occurred in $2.8 \%$ of the cases involving thoracic surgery with radical systematic lymphadenectomy. The role of pneumonectomy with mediastinal lymph node dissection in the development of chylothorax is unclear. Le Pimpec-Barthes et al. encountered a significantly higher incidence of chylothorax when pulmonary resection consisted of a pneumectomy compared with (bi)lobectomy (5/8 vs. $1 / 18$ ) [11]. In the patients in the studies conducted by Cerfolio et al. and Shimizu et al., pneumonectomy did not increase the incidence of chylothorax [3,12].

Postoperative chylothorax during the initial operation can be prevented by performing careful dissection and liberal clipping of lymphatic vessels, particularly in the posterior mediastinum. Guo et al. reported that thoracic duct ligation during VATS-esophagectomy for cancer is an effective and safe method for preventing chylothorax [16]. However, there is no consensus or formal guidelines regarding the safe preparation of lymph nodes for lung cancer to prevent postoperative chylothorax.

In patients with postoperative or post-traumatic chylothorax, some authors considered the anatomical location of the thoracic duct injury. Ruan et al. recommends lymphangiography in patients with intractable spontaneous chylothorax [17]. They found that this diagnostic procedure may facilitate the occlusion of the leakage site and the prediction of the occurrence of adverse events due to thoracic duct ligation. We think that radiation therapy for secondary chylothorax does not require any type of leakage detection.

Current treatment modalities for postoperative chylothorax include conservative, interventional and surgical therapies.

The principles of conservative chylothorax treatment include efficient drainage, inflation of the lung to decrease 


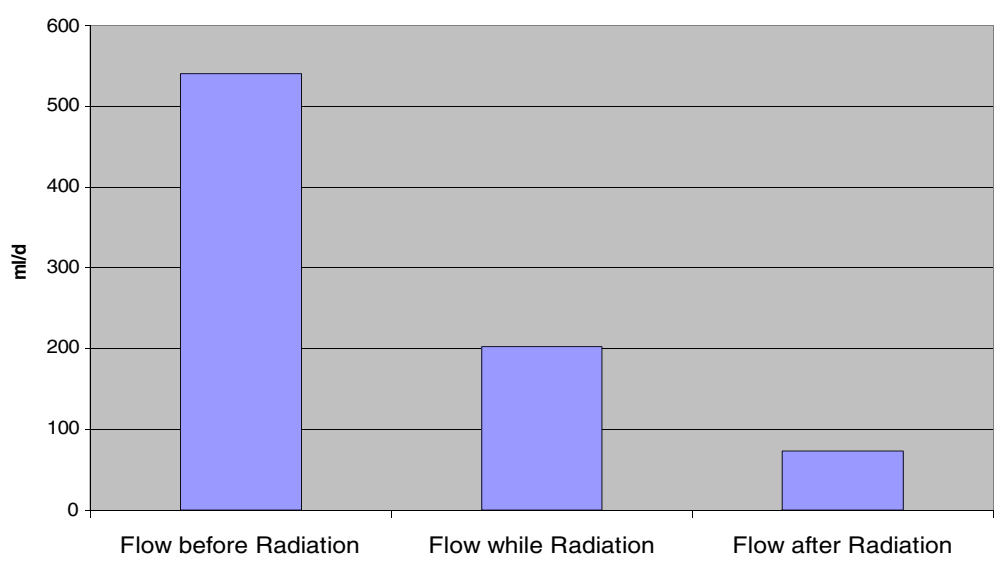

Figure 1 Mean flow of the drainage fluid in $\mathrm{ml} /$ die before, while and after radiation.

the dead space in the thoracic cavity and to promote adhesion of the lung or pleura to the thoracic duct injury, and cessation of flow (diet/parenteral nutrition) through the thoracic duct to accelerate fistula closure. Conservative treatment must be initiated at the time of diagnosis and results in resolution of the chylothorax in $23 \%$ to $70 \%$ of cases (Table 4 , if $\mathrm{n}>1$ ).

Interventional/surgical management should be adopted if conservative management fails. The interventional therapies include VATS for pleurodesis, percutaneous lymphangiography and radiotherapy. Schoellnast et al. reported a $50 \%$ success rate after needle disruption of the cisterna chyli with subsequent resolution of the chylothorax [20]. Cope found that two thirds of patients presenting with life-threatening chylothorax can be safely treated with percutaneous transabdominal thoracic duct blockage [19]. Promotion of adhesions of the lung and pleura to the thoracic duct injury by pleurodesis may play an important role in the treatment of chylothorax. Talc pleurodesis is successful in $73 \%$ to $83 \%$ of all cases $[13,14]$. The injection of OK-432, which is a heat- and penicillin-treated lyophilized preparation of the $\mathrm{Su}$ strain of Streptococcus pyogenes, into the thoracic cavity is effective and safe in managing postoperative chylothorax and exhibited a success rate of $87 \%$ [12]. Other therapeutic options such as the intrapleural instillation of octreotide/somatostatin, streptokinase or fibrin glue therapy were only published as case reports $[18,21,22]$.

Surgical treatment generally involves ligation of the thoracic duct. Thoracic surgeons often recommend reoperation to ligate the thoracic duct when conservative therapy fails [3,12,15]. Surgical intervention offers better results than conservative management when the daily chyle flow exceeds $500 \mathrm{ml} /$ day in adults [12]. Zabeck et al. found that in postoperative chylothorax with a high flow of $>900 \mathrm{ml} /$ day, repeat surgery should be performed as soon as possible because conservative management is likely to be unsuccessful [15].

Radiotherapy of inguinal lymph fistulas is a wellestablished, effective and well-tolerated treatment option. Because fistulas completely close after radiotherapy, this procedure is a good alternative to other conservative treatment modalities [5]. The motivations for our study were some well documented case reports that described the successful management of malignant chylothorax with radiotherapy [6,7].

Analogously, there are several potential advantages of using radiation to treat chylothorax. The early use of radiation therapy may rapidly arrest the progression of chylothorax and allow the patient to avoid invasive

Table 3 Incidence of secondary chylothorax following thoracic surgery

\begin{tabular}{lll}
\hline Author (year) [Reference] & Kind of ymphnodedissection & Incidence of postoperative chylothorax (\%) \\
\hline Bollen et al. 1993 [9] & Mediastinal lymph node dissection & 3 \\
\hline Izbicki et al. $1994[10]$ & Radical systematic lymphadenectomy & 1.2 \\
\hline Cerfolio et al. $1996[3]$ & n.a. & 0.26 \\
\hline Le Pimpec-Barthes et al. 2002 [11] & Mediastinal lymph node dissection & 0.65 \\
\hline Shimizu et al. $2002[12]$ & Mediastinal lymph node dissection \\
\hline Paul et al. 2009 [13] & Three-field dissection \\
\hline Akin et al. 2011 [14] & Mediastinal lymph node dissection \\
\hline Own results & Radical systematic lymphadenectomy \\
\hline
\end{tabular}


Table 4 Treatment modalities and outcomes for secondary chylothorax

\begin{tabular}{|c|c|c|c|}
\hline Treatment & Author (year) [Reference] & $\mathrm{n}=$ & Success rate (\%) \\
\hline \multicolumn{4}{|l|}{ Conservative } \\
\hline Diet/parenteral nutrition & Cerfolio et al. 1996 [3] & 47 & 28 \\
\hline Somatostatin-Infusion & Rimensberger et al. 1998 [18] & 1 & 100 \\
\hline Medium Chain Triglycerides Diet & Le Pimpec-Barthes et al. 2002 [11] & 26 & 50 \\
\hline Parenteral nutrition & Shimizu et al. 2002 [12] & 26 & 23 \\
\hline Diet/parenteral nutrition & Chalret du Rieu et al. 2011 [2] & n.a. & 70 \\
\hline Diet/parenteral nutrition & Zabeck et al. 2011 [15] & 37 & 32 \\
\hline \multicolumn{4}{|l|}{ Interventional } \\
\hline Percutaneous Embolization & Cope 2004 [19] & 60 & 65 \\
\hline Pedal Lymphangiography & Le Pimpec-Barthes et al. 2002 [11] & 7 & 57 \\
\hline Pleurodesis (OK-432) & Shimizu et al. 2002 [12] & 15 & 87 \\
\hline Pleurodesis (talc) & Paul et al. 2009 [13] & 6 & 83 \\
\hline Pleurodesis (talc) & Akin et al. 2011 [14] & 26 & 73 \\
\hline Direct lymphangiography & Schoellnast et al. 2011 [20] & 2 & 50 \\
\hline \multicolumn{4}{|l|}{ Surgery } \\
\hline Duct ligation & Cerfolio et al.1996 [3] & 32 & 94 \\
\hline Duct ligation & Shimizu et al. 2002 [12] & 5 & 100 \\
\hline Duct ligation/Loc. Suture & Le Pimpec-Barthes et al. 2002 [11] & 5 & 83 \\
\hline Duct ligation & Paul et al. 2009 [13] & 22 & 95 \\
\hline Duct ligation & Akin et al. 2011 [14] & 7 & 100 \\
\hline
\end{tabular}

procedures. Up to $11 \%$ of the patients with postoperative chylothorax underwent repeat surgical procedures due to complications, and $9 \%$ experienced recurrence of their chylothorax [15]. Shimizu et al. reported that complications following VATS pleurodesis and repeat thoracotomy occurred in $15 \%$ of cases [12].
Accordingly, the median length of hospital stay was shorter in our group (median, 18 [range 11-30] days) compared with the group that underwent (redo) operation in the studies of Kashiowanoha (19 [range 12-36] days) and Heidelberg (26 [range 15-205] days), respectively $[12,15]$.

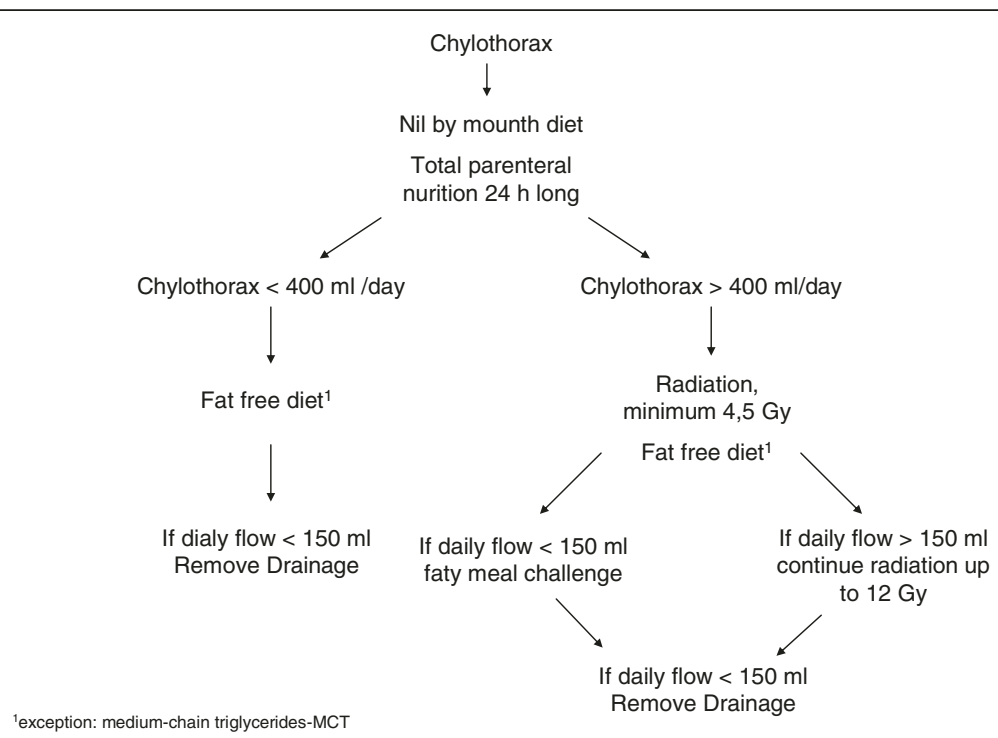

Figure $\mathbf{2}$ Therapy recommendation for postoperative chylothorax. 
The major disadvantage to using radiation therapy for chylothorax is the possibility for acute and long-term side effects that vary by treatment site. On the other hand, no patient developed in our study radiation side effect (e.g. pneumonitis) after the low-dose radiotherapy. While moderate/severe radiation-induced side effects are rare, the potential for secondary malignancy and growth restriction should be considered before administering high-dose radiation therapy especially to children.

The great advantages of radiation therapy with a maximum of 12 Gy include the low incidence of acute and long-term side effects. After a mean follow-up of 6 months, no recurrent chylothorax or other complications were observed in any of the seven patients. All of these patients reported a very good quality of life in an outpatient interview.

Future studies should investigate the required minimum energy that is required to eliminate the chyle leakage.

\section{Study limitation}

The limitation of our study was the small number of patients.

\section{Conclusion}

Our results suggest that radiotherapy in combination with diet in the treatment of postoperative chylothorax is very safe, rapid and successful. Our therapy recommendation is summarized in Figure 2. This interventional procedure can obviate repeat major thoracic surgery and shorten hospital stays and could be the first choice in the therapy of postthoracotomy chylothorax.

\section{Competing interest}

All co-authors have seen and agreed with the contents of the manuscript and there is no financial interest to report.

\section{Authors' contributions}

CG, MA, and GH participated in the design of the study. TS and RS participated in the sequence alignment and drafted the manuscript. ZS, HH and MR conceived of the study and participated in its design and coordination. RN participated in surgery. All authors read and approved the final manuscript.

\section{Author details}

'Department of Thoracic Surgery, Hospital Barmherzige Brüder Regensburg, Prüfeningerstraße 86, 93049, Regensburg, Germany. ${ }^{2}$ Department of Radiotherapy, Hospital Barmherzige Brüder Regensburg, Prüfeningerstraße 86, 93049, Regensburg, Germany. 'Department of Thoracic Surgery, University Regensburg, Franz-Josef-Strauss-Allee 11, 93053, Regensburg, Germany.

Received: 19 November 2012 Accepted: 26 March 2013 Published: 8 April 2013

\section{References}

1. McGrath EE, Blades Z, Anderson PB: Chylothorax: aetiology, diagnosis and therapeutic options. Respir Med 2010, 104:1-8.

2. Chalret Du Rieu M, Mabrut JY: Management of postoperative chylothorax. J Visc Surg 2011, 148(5):e346-e352.

3. Cerfolio RJ, Allen MS, Deschamps C, Trastek VF, Pairolero PC: Postoperative chylothorax. J Thorac Cardiovasc Surg 1996, 112:1361-1365.
4. Khurana H, Mishra S, Jain R, Goyal GN, Bhatnagar S: Management of postoperative chylothorax in a patient with carcinoma of thyroid and lymphadenopathy - a case report. Middle East J Anesthesiol 2009, 20:121-123.

5. Dietl B, Pfister K, Aufschläger C, Kasprzak PM: Radiotherapy of inguinal lymphorrhea after vascular surgery. A retrospective analysis. Strahlenther Onkol 2005, 181:396-400.

6. Gerstein J, Kofahl-Krause D, Fruhauf J, Bremer M: Complete remission of a lymphoma-associated chylothorax by radiotherapy of the celiac trunk and thoracic duct. Strahlenther Onkol 2008, 184:484-487.

7. Cigarral C, Montero A, Salas C, Rodriguez G, de la Torre A: Chylothorax due to metastasic prostate carcinome: an unusual complication. Clin Trans/ Oncol 2009, 11(11):767-769.

8. Doerr CH, Allen MS, Nichols FC 3rd, Ryu JH: Etiology of chylothorax in 203 patients. Mayo Clin Proc 2005, 80:867-870.

9. Bollen EC, Van Duin CJ, Theunissen PH, Vt Hof-Grootenboer BE, Blijham GH: Mediastinal lymph node dissection in resected lung cancer: morbidity and accuracy of staging. Ann Thorac Surg 1993, v:961-966.

10. Izbicki JR, Thetter O, Habekost M, Karg O, Passlick B, Kubuschok B, Busch C, Haeussinger K, Knoefel WT, Pantel K, et al: Radical systematic mediastinal lymphadenectomy in non-small cell lung cancer: a randomized controlled trial. Br J Surg 1994, 81:229-235.

11. Le Pimpec-Barthes F, D’Attellis N, Dujon A, Legman P, Riquet M: Chylothorax complicating pulmonary resection. Ann Thoracic Surg 2002, 73:1714-1719.

12. Shimizu K, Yoshida J, Nishimura M, Takamochi K, Nakahara R, Nagai K: Treatment strategy for chylothorax after pulmonary resection and lymph node dissection for lung cancer. J Thorac Cardiovasc Surg 2002, 124:499-502.

13. Paul S, Altorki NK, Port JL, Stiles BM, Lee PC: Surgical management of chylo-thorax. Thorac Cardiovasc Surg 2009, 57:226-228.

14. Akin H, Olcmen A, Isgorucu O, Denizkiran I, Dincer I: Approach to patients with chylothorax complicating pulmonary resection. Thorac Cardiovasc Surg 2012, 60(2):135-139.

15. Zabeck H, Muley T, Dienemann $H$, Hoffmann $H$ : Management of chylothorax in adults: when is surgery indicated? Thorac Cardiovasc Surg 2011, 59:243-246.

16. Guo W, Zhao YP, Jiang YG, Niu HJ, Liu XH, Ma Z, Wang RW: Prevention of postoperative chylothorax with thoracic duct ligation during videoassisted thoracoscopic esophagectomy for cancer. Surg Endosc 2012, 26(5):1332-1336

17. Ruan Z, Zhou Y, Wang S, Zhang J, Xu W: Clinical use of lymphangiography for intractable spontaneous chylothorax. Thorac Cardiov Surg 2011, 59(7):430-435

18. Rimensberger PC, Müller-Schenker B, Kalangos A, Beghetti M: Treatment of a persistent postoperative chylothorax with somatostatin. Ann Thorac Surg 1998, 66:253-254.

19. Cope C: Management of chylothorax via percutaneous embolization. Curr Opin Pulm Med 2004, 10(4):311-314.

20. Schoellnast H, Maybody M, Getrajdman Gl, Bains MS, Finley DJ, Solomon SB: Computed tomography-guided access to the cisterna chyli: introduction of a technique for direct lymphangiography to evaluate and treat chylothorax. Cardiovasc Intervent Radiol 2011, 34(Suppl 2):S240-S244.

21. Kuan YC, How S, Ng T, Fauzi A: Intrapleural streptokinase for the treatment of chylothorax. Respir Care 2011, 56:1953-1955.

22. Akaogi E, Mitsui $K$, Sohara $Y$, Endo S, Ishikawa S, Hori M: Treatment of postoperative chylothorax with intrapleural fibrin glue. Ann Thorac Surg 1989, 48:116-118.

doi:10.1186/1749-8090-8-72

Cite this article as: Sziklavari et al:: Radiotherapy in the treatment of postoperative chylothorax. Journal of Cardiothoracic Surgery 2013 8:72. 